\title{
Being in nature together: Photovoice of an Icelandic youth nature club
}

Jessica Faustini Aquino, Hólar University, Department of Rural Tourism \& Icelandic Seal Center

\section{Introduction}

Educators who focus on creating connections between youth and nature have found that such connections through hands-on learning (or experiences) may lead to greater empathy and stewardship (Barane, Hugo, \& Clemetsen, 2018; Sobel, 1996). There is no doubt that global climate change is a concern for youth, as children and youth in the developing world are among the most vulnerable to its effects (Sanson, Wachs, Koller, \& Salmela-Aro, 2018). Education can be transformative if people are given chances to acquire it in a fair and equitable manner, and youth have the right to be given opportunities to become aware of local issues that affect them within their own cultural context. These opportunities, of course, create a spillover effect: learning about local issues leads to learning about global issues. Freire (1970) cultivated learners' social transformation using education as a process of open dialogue. This creates a space where learning socially in action can be combined with reflection, which leads to praxis (Freire, 1970). Learning reinforced through practice becomes hope, which is, as Freire explains, an ontological need (Freire, 1994). Without hope there is no action, but people who work with children and youth, and who believe that education is transformative, have hope. Through reflection and action, we practice empathy and stewardship - we build the foundations for hope. Educators have a responsibility to offer opportunities for experiences that will give youth an awareness of their own strength and develop their capacity and resilience.

This research note describes the efforts of a rural community in Northwest Iceland to establish a youth nature club called Húnaklúbburinn. The main goals of Húnaklúbburinn (Hunaklub) are to develop local identity through place-based education and to increase awareness of how youth can contribute to the sustainable development of their community. I am the director and one of the founders of Hunaklub, and I have many years of experience working with youth in nature. The youth described here are between the ages of 13-16 and are from the community of 
Húnaping vestra. Joining the club is voluntary, and its main activity is outdoor recreation that takes place during their leisure time. Every effort is made to aid in full participation and inclusion. Often, only a few small adjustments are required to be inclusive of all abilities and skills (including physical, emotional, social, and developmental). For example, the club uses multisensory activities, and members partner with peers for extra assistance.

In 2018, Hunaklub was awarded funding to participate in an Erasmus+ youth exchange where a Swedish youth group came to Iceland for one week to participate in activities in nature (see Aquino, 2019). We selected this event to capture the lived experiences of the exchange with the goal of learning how to better incorporate youth in the leadership and ownership of their club. Youth leadership in program development creates ownership, builds capacity, and promotes empowerment. The establishment of the club was initiated by adults, but we have since worked on transitioning the club to foster shared decisions with young people. Photovoice was explored as a strategy for the integration of the youth in the development of their club because of its method of reflection and dialogue though photographs. The outcomes of the photovoice activity were more than expected, and a deeper understanding of how youth interact in nature was also discovered. In this research note, the development of Hunaklub as a concept is discussed along with a description of how photovoice was used as a strategy for empowering youth in the club's overall development.

\section{Hunaklub's philosophy}

Hunaklub was established in 2016 through local efforts involving the municipality's Youth Association of Vestur Húnavatnssýsla (U.S.V.H.), a local youth center (Félagsmiðstöðin Óríon), a community-owned nonprofit (Icelandic Seal Center), and Hólar University. Members of Hunaklub's board are people from the local community who have an interest in strengthening youth leisure and recreational programs in general, and who understand that this activity contributes positively to the youth's development and quality of life. Programs that encourage youth involvement in community development have been shown to have a positive effect on youth resilience and coping skills, making them ready for the challenges ahead (Christens \& Dolan, 2011). Hunaklub views youth as a resource and increasing their exposure to developmental opportunities as an investment.

Hunaklub is founded on two principles. First, youth have the right and responsibility to take part in shaping their own futures and the futures of their communities (UNICEF, 1989). Secondly, through direct interaction with nature, youth develop a genuine appreciation of the natural environment and a sense of their own competence (Hart, 1997). Each year, the club develops a theme where activities are designed holistically around how youth learn in nature. The added element of travel afforded by the Erasmus+ grant has allowed an opportunity to learn about other cultural landscapes and ecosystems. Furthermore, on an organizational level, the club was influenced by the Swedish youth leaders, as they gave us strategies for how to empower the youth 
by having Youth Leaders and youth ${ }^{1}$ share decisions on the development of projects and putting the responsibility of learning in the youth's own hands. In a sense, Hunaklub's 2018 program was co-created, combining the two youth groups' organizational philosophies, methods, and dialogue. Knowing and being are inseparable (Rautio, 2013), and being in nature offers opportunities to gain a deeper understanding of how to preserve and protect the environment. Learning with nature entails working together in natural spaces (Warden, 2015). Learning together offers chances to "unveil opportunities for hope, no matter what the obstacles may be" (Freire, 1994, p. 3). Education is part of the life of communities and ecosystems - it is not abstracted from them (Shannon \& Galle, 2017). Together, through reflection and action, we can practice skills to become future leaders. We nurture hope.

Interaction between youth and the natural world is valuable, while reflection that takes place after such interaction helps youth to appreciate their lived experiences of being in nature. Sobel (1996) argues that without giving children the chance to be in nature, teaching environmental issues may only lead to distancing them from what we hope they would learn to protect. What Hunaklub has observed is that opportunities to socialize together in nature are essential, as they help to co-create an understanding of how to be in and learn from nature. Learning is mobile - moving from indoors to outdoors, from local to global, and from individual to social. Additionally, this connection with nature, through the practice of place-based education and outdoor recreation, helps to develop the skills needed for leadership in the community.

Place-based education is deeply rooted in environmental education; however, it also acknowledges that humans are connected to and have influence on ecosystems (Shannon, 2017), while the boundaries of place are elastic, allowing it to grow (the global in the local) or shrink (the local in the global) (Adams \& McGehee, 2017). Hunaklub sees learning in nature as action toward sustainability. Youth clubs should work holistically within a community involving youth, educators, guardians, and policymakers to arrive at solutions for environmental questions, problems, and issues (Davis, 1998). This can be somewhat challenging, because Youth Leaders and educators may feel that they need to know everything about the environment or science before they can teach it. However, engaging people with nature is less about teaching what you know than how you learn it. Place-based education and outdoor recreation are about being in nature and about community building. Young people should be offered opportunities to practice their diverse skills through engaging with nature and perceiving possibilities for engagement (Rantala \& Puhakka, 2019). Children need to experience nature to connect with it, to be "hopelessly entangled in the mesh" (Morton, 2010, p. 293). Youth leaders participate in community development by connecting youth with others who have valuable skills and abilities to share and who have an interest in working with youth on community development.

1 Here I define "Youth Leaders" as educators who work with youth using informal and non-formal education during youth's leisure time, whereas "youth" are the learners who have voluntarily chosen to take part in learning during their leisure time. Defining youth leaders as educators and youth as learners in this manner acknowledges the link that Freire (1970) made of the power dynamics between educator (powerful) and student (less powerful). The acknowledgment of this potential power inequality between educators and students helps to transform oppressive forms of education into a fair and equitable learning environment (i.e., education as co-creation). 


\section{Photovoice method}

Photovoice is both a technique and a process, first developed by Wang and Burris (1997) and used in the field of community development to help create change by giving a voice to those who are not often heard (Krutt, Dyer, Arora, Rollman, \& Jozkowski, 2018). Photography and discussion were used during the youth exchange to enable self-expression, reflect on experiences, promote critical dialogue for evaluation, and further program development led by the youth. An international youth exchange had never been done before in the community of Húnaping vestra, so until this youth exchange took place, it was difficult to understand what type of impact or effect it would have. Therefore, it was essential to use an evaluation method where both youth and Youth Leaders could visually see and discuss the process of the youth exchange. Visually seeing and reflecting on the lived experiences of the exchange enables a better understanding of how youth engage in activities, and it helps Youth Leaders evaluate how they can empower the youth to further the development of the club in the future. Participant engagement with photographs and dialogue has been shown to help increase self-expression and self-development through reflection, as well as ownership, knowledge creation, and polysemic data (Rydzik, Pritchard, Morgan, \& Sedgley, 2013). The use of photovoice as a method of evaluation was intended to engage both youth and Youth Leaders in the process of social learning, analysis, and empowerment (Rose, 2016). Hunaklub youth have a variety of different abilities, talents, likes, and strengths. Some of the youth need help in verbally expressing themselves. To help with inclusion, enable full participation, and facilitate self-expression, photovoice was considered to be appropriate for this project because it has been used by Krutt and her colleagues (2018) as a method of evaluation while empowering adults with autism to discuss their community center and its services.

Both youth groups (Swedish and Icelandic) used their selected photos for a photovoice exhibition open to their home communities. However, only the interviews with the Icelandic youth and the process of photovoice as an evaluation method are described in this research note. Meetings with the parents, Youth Leaders, and youth occurred separately to inform each group of the photovoice method and how it would be used to create an exhibition after the youth exchange. Both parents and youth signed a document giving consent to participate in the photovoice. Nonetheless, the youths were reminded that the photovoice was voluntary and they could choose not to participate or to drop out at any time. A total of 32 youth participated in the exchange (17 Icelandic and 15 Swedish), with 14 of the Icelandic youth choosing to participate in the photovoice. A total of 64 photos were used for discussion with the Icelandic youth, while a total of 191 photos were used for the photovoice exhibition in Iceland, combining both Icelandic and Swedish youth photos.

Photovoice was explained again once the participants were given cameras during the exchange. The objectives were "to use photos and discussions for youth-led development of Hunaklub, and to help tell a story of the youth exchange." In order for the photos to be individualistic and to be a reflection of their own voices, it was decided that the instructions for what to take pictures of would be kept very simple. When the youth were given camera, they were told to "take pictures of anything that happens today and pick 3-5 of your favorite photos for discussion." The 
Icelandic youth leaders later met with the youth for discussions. Handwritten notes were taken, which were then paired up with the corresponding photos.

Discussion of the photos and evaluation of the youth exchange was also conducted during four workshops to contextualize the photos and prepare for the exhibition. To start, there was a kickoff workshop where all of their photos were shown together as a group using a projector. After the group discussion, the youth voted on their favorite photo and the photo that best represents Hunaklub. These two photos were then printed as posters and awarded to the youth who had originally taken each photo. During the next three workshops, youth were asked to use their photos as a form of storytelling and to place them according to what they were trying to say. Next, the youth were asked to write words, poetry, or drawings to describe either individual photographs or the photos as a whole (Figure 1). At the final workshop, a meeting was held with just the Icelandic youth leaders to discuss observations and have a final discussion of the photovoice overall.

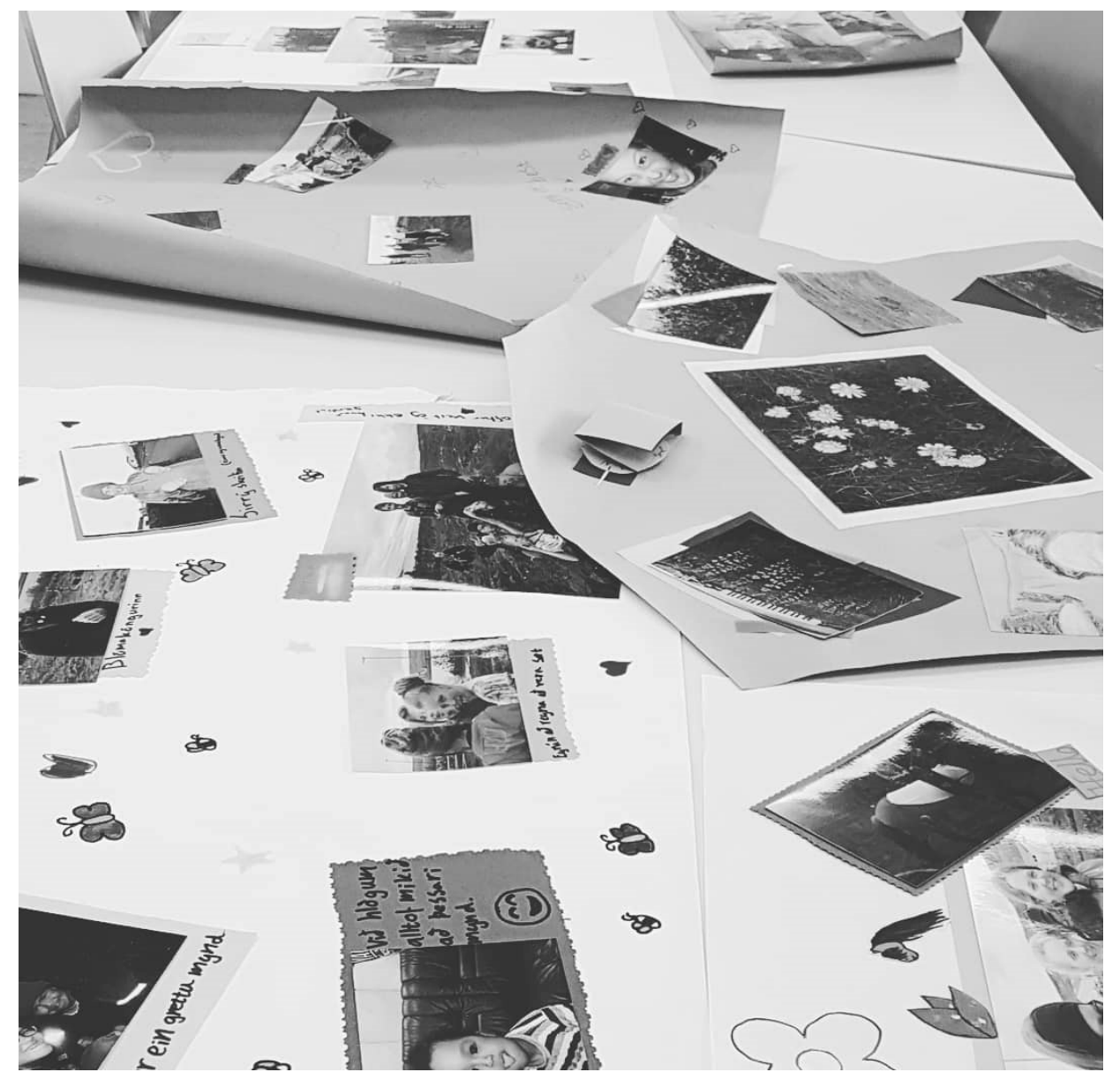

Figure 1. After the final workshop in preparation for the photovoice exhibition. (Photo: author.) 


\section{Results}

The interviews and photos were first analyzed separately, and then the two analyses were explored together to see relationships between the photos and the interviews. Dividing the data in this manner allowed the specific roles of the photographs and the interviews to show different trends and for the relationships between them to be seen more directly (Rose, 2016). A codebook was used to create themes and codes for the photographs. The photos were coded with themes, which were then reduced to four overall themes. Many photos had a mixture of themes. The themes most often identified were nature (61\%), people (47\%), and silly (31\%). Two other themes noted less frequently were activity (5\%) (representing people doing an activity that was part of the exchange), and object (1\%) (a photo of an object not found in nature).

As the Icelandic youth group is from a small rural community of around 1,200 people, it would not be ethical to reproduce many of the direct quotes because of the impossibility of keeping the quotes confidential. Therefore, this section will discuss a generalization of the interviews using their words clustered together as an aggregate. Using the youth's discussion about their photos created more in-depth themes than what was created for the photos alone. The theme most often spoken about was being in nature together. In this theme, the youth talked about how the place was beautiful or how it was "nice to be there," to walk and to be with friends. The words that were used to describe these photos were "beautiful," "making," "walking," "talking," "together," "be there," "place," and "landscape." The second most mentioned theme involved photos that show off nature. The participants used words such as "beautiful," "nice," "good," "colors," and "it's Icelandic" to describe important natural and cultural landmarks, animals, and scenery. The way the youth described why they picked these photos was more about how the images "show off" nature. Next was the theme captures a moment. These photos were described as the youths' favorites because they each captured a moment that was silly or funny and made them laugh with their friends. Words that they used to describe this theme were "funny," "silly," "cute," "friends," "flowers in hair" or "flowers in beard." The final theme was it's a good photo. In this theme, the youth talked about the photo as, quite simply, a good photo. They talked about the aesthetics of the photo using words such as "good," "different," "cool," and "scenery."

The youth were asked about what they liked and disliked about the youth exchange two times during the photovoice evaluation. The first time was when they were interviewed one-onone with me or with another Youth Leader and were asked, "What was your favorite thing that happened today?" They were interviewed together as a group to discuss the question, "What did you like about the youth exchange?" The responses were divided into three themes. In the first theme, being in nature together, youth talked about how they liked being in or interacting with nature with friends. The words that they used most often were "kids", "friends," "garden," "spider," and "being here together." The next theme was activity. The youth enjoyed the activities the most when they were actively engaged. They used words such as "horse gymnastics," "being part of the show," "birding," "taking pictures," "horseback riding," and "games at the horse arena." A few mentioned that they liked it because the "entire group was doing it together." The final theme of nature was less often mentioned. This theme describes youth being in nature individually rather 
than together. After the workshops, Hunaklub's youth hosted a photovoice exhibition ${ }^{2}$ where they had a chance to talk to the community about their experience with the youth exchange.

The photos helped to visually represent the lived experience of the youth group during the youth exchange, and they show a strong link between nature and socialization. The dialogue and reflection during the photovoice demonstrated that the majority of the Icelandic youth felt that their favorite thing about the experience was being in nature together, showing an essential link to experiencing nature as a social activity. The next most favorite thing the youth mentioned was engaging in activities and doing these activities together as a group, again showing how important socialization is to the youth.

\section{Discussion and conclusion}

Checkoway (2011) describes the importance of participation as something that helps youth to develop "their expertise, enables them to exercise their rights as citizens, and contributes to a more democratic society" (2011, p. 340). The main goals of using photovoice as an evaluation method during the youth exchange were to create a space for open dialogue and to explore a method to help integrate youth in the decisions of the development of their club. However, through the process of photovoice, we also learned more about the lived experiences of youth in nature. Youth clubs have an important role in building awareness of and capacity for how youth can contribute to the sustainable development of their community, and this can begin with giving them leadership in the development of their own clubs and projects. Place-based education is about creating inclusiveness and a more sustainable environment through building compassion, responsibility, and respect that includes all members of the community.

Youth learn about science in classrooms passively, but knowledge is best reinforced through active learning in the natural environment, which sparks a lifelong interest in the natural sciences and outdoor activities (Davis, 1998). Developing a relationship with nature, and with each other, may help to deepen an understanding of the interaction between humans and nature. If cultural understanding is created socially, then cultural understanding of nature is also understood together. Culture and nature are intertwined, and learning in nature can be transformative. Youth nature clubs have the potential to create a lasting impact on the participants' lives because these experiences with nature are crucial in developing an awareness of environmental issues, fostering biocentric values and attitudes, and sparking actions toward stewardship. Learning and acting in nature together is part of knowing and developing with nature. Educators using place-based education as their practice should provide a learning environment that gives youth opportunities for learning socially in action combined with reflection for praxis. This approach implies a respect for the knowing of lived experiences (Freire, 1994), and in this way, it empowers youth, gives them confidence, and integrates them in the development of the club the foundations of hope.

Barane, Hugo, and Clemetsen (2018, p. 24) contend that "an overarching aim of ecological literacy is to bring about a fundamental change in our relationship with the world, so that we

2 To see photos from the Photovoice Exhibition, please go to http://bit.ly/IcelandPhotovoice. 
may interact considerately with humans and animals." Youth being active in nature can positively affect their well-being, and it helps to develop their relationship with the natural world (Rantala \& Puhakka, 2019). Additionally, socialization through leisure activities has been shown to have a direct positive effect on youths' quality of life (Brajša-Žganec, Merkaš, \& Šverko, 2011). Youth who are active in nature and are afforded the chance to reflect on it may have a greater impact on the community's understanding of the environment, because they will teach what they have discovered to others (parents, siblings, friends, the community, etc.), either directly through events such as the photovoice exhibit (Figure 2) or indirectly through conversations and actions.

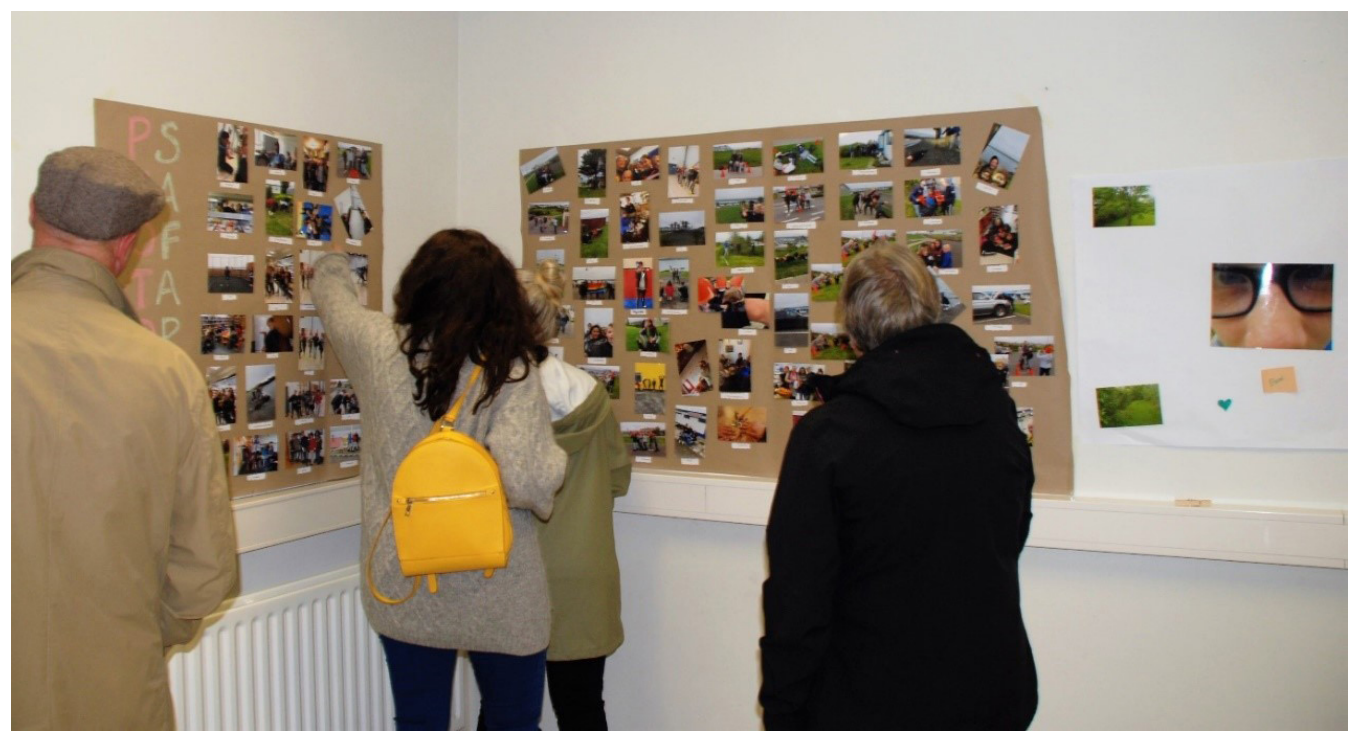

Figure 2. Photovoice exhibition during the Eldur Festival in Húnaping vestra. (Photo: author.)

\section{References}

Adams, J. P., \& McGehee, M. (2017). Seeking peace, seeking justice: Place-based pedagogies and global connections. In D. Shannon \& J. Galle (Eds.), Interdisciplinary approaches to pedagogy and place-based education (pp. 147-166). Cham: Springer International Publishing. https://doi. org/10.1007/978-3-319-50621-0

Aquino, J. F. (2019). Icelandic culture and nature KA1: Youth exchange. Final report. Sauðárkrókur. https://doi.org/https://doi.org/10.13140/RG.2.2.27133.00488

Barane, J., Hugo, A., \& Clemetsen, M. (2018). Creative place-based environmental education: Children and schools as ecopreneurs for change. Gloucestershire: Hawthorn Press.

Brajša-Žganec, A., Merkaš, M., \& Šverko, I. (2011). Quality of life and leisure activities: How do leisure activities contribute to subjective well-being? Social Indicators Research, 102, 81-91. https:// doi.org/10.1007/s11205-010-9724-2 
Checkoway, B. (2011). What is youth participation? Children and Youth Services Review, 33, 340-345. https://doi.org/10.1016/j.childyouth.2010.09.017

Christens, B. D., \& Dolan, T. (2011). Interweaving youth development, community development, and social change through youth organizing. Youth \& Society, 43, 528-548. https://doi. org/10.1177/0044118X10383647

Davis, J. (1998). Young children, environmental dducation, and the future. Early Childhood Education Journal, 26, 117-123. https://doi.org/10.1023/A:1022911631454

Freire, P. (1970). Pedagogy of the oppressed. New York: Continuum.

Freire, P. (1994). Pedagogy of hope: Reliving pedagogy of the oppressed. New York: Continuum.

Hart, R. A. (1997). Children's participation: The theory and practice of involving young citizens in community development and environmental care. London: Taylor \& Francis.

Krutt, H., Dyer, L., Arora, A., Rollman, J., \& Jozkowski, A. C. (2018). PhotoVoice is a feasible method of program evaluation at a center serving adults with autism. Evaluation and Program Planning, 68, 74-80. https://doi.org/10.1016/j.evalprogplan.2018.02.003

Morton, T. (2010). Thinking ecology: The mesh, the strange stranger, and the beautiful soul. Collapse (VI), 265-293.

Rantala, O., \& Puhakka, R. (2019). Engaging with nature: nature affords well-being for families and young people in Finland. Children's Geographies. https://doi.org/10.1080/14733285.2019.168 5076

Rautio, P. (2013). Children who carry stones in their pockets: On autotelic material practices in everyday life. Children's Geographies, 11, 394-408. https://doi.org/10.1080/14733285.2013.812278

Rose, G. (2016). Visual methodologies: An introduction to researching with visual materials (4th ed.). London: Sage.

Rydzik, A., Pritchard, A., Morgan, N., \& Sedgley, D. (2013). The potential of arts-based transformative research. Annals of Tourism Research, 40, 283-305. https://doi.org/10.1016/j.annals.2012.09.006

Sanson, A. V., Wachs, T. D., Koller, S. H., \& Salmela-Aro, K. (2018). Young people and climate change: The role of developmental science. In S. Verma \& A. C. Petersen (Eds.), Developmental dcience and sustainable development goals for children and youth (pp. 115-137). Cham: Springer. https://doi.org/10.1007/978-3-319-96592-5_6

Shannon, D. (2017). Teaching on the farm: Farm as place in the sociology of food and sustainability. In D. Shannon \& J. Galle (Eds.), Interdisciplinary approaches to pedagogy and place-based education (pp. 115-137). Cham: Springer International Publishing. https://doi.org/10.1007/9783-319-50621-0

Shannon, D. \& Galle, J. (2017). Where we are: Place, pedagogy, and the outer limits. In Interdisciplinary approaches to pedagogy and place-based education (pp. 1-8). Cham: Springer International Publishing. https://doi.org/10.1007/978-3-319-50621-0_1

Sobel, D. (1996). Beyond ecophobia: Reclaiming the heart in nature education. Great Barrington, MA: The Orion Society and The Myrin Institute. 
UNICEF. (1989). The convention on the rights of the child. Cornell University ILR School. https://doi. org/10.2307/4065371

Wang, C., \& Burris, M. A. (1997). Photovoice: Concept, methodology, and use for participatory needs assessment. Health Education and Behavior, 24, 369-387.

Warden, C. (2015). Learning with nature: Embedding outdoor practice. London: Sage. 